\title{
GASTRONOMIC VERBAL METAPHOR AS A REALIZATION MEANS OF CULTURE GASTRONOMIC CODE IN THE FRENCH LANGUAGE
}

\author{
Olga A. Dormidontova \\ Lipetsk State Pedagogical P. Semenov-Tyan-Shansky University, Lipetsk, Russia
}

\begin{abstract}
The paper is devoted to the urgent problem of diverse reflection of the linguistic and cultural worldview. The research purpose is to characterize semantic and structural peculiarities of the verbal gastronomic metaphor as the manifestation mechanism of the gastronomic metaphoric code of the French linguistic culture. The realization of the research tasks has been achieved through the use of the corpus of phraseological units with a "gastronomic verb" as a core component. Semantic peculiarities of the verbal gastronomic metaphor have been examined on the basis of a group of verbs that define meals: a semantic classification of such metaphors has been worked out. It has been suggested that the most diverse metaphors are those that define person's internal and external character traits as well as state and relationship with other people. Structural peculiarities of a verbal gastronomic metaphor have been examined on the basis of a group of verbs meaning multiple cooking techniques and actions: cognitive supports of such metaphors have been established, models and sub-models of their formation have been revealed; it has been determined that structural diversity is the peculiarity of a gastronomic metaphor that is formed with a transitive verb as a core component. It has been proved that gastronomic metaphor nominating a wide variety of objects, signs, phenomena, processes, the world, serves as a marker of French linguistic culture.

Key words: French language, linguistic culture, linguistic worldview, culture code, metaphor, gastronomic metaphor, metaphorical model, cognitive supports.

Citation. Dormidontova O.A. Gastronomic Verbal Metaphor as a Realization Means of Culture Gastronomic Code in the French Language. Vestnik Volgogradskogo gosudarstvennogo universiteta. Seriya 2, Yazykoznanie [Science Journal of Volgograd State University. Linguistics], 2018, vol. 17, no. 4, pp. 146-152. (in Russian). DOI: https://doi.org/10.15688/jvolsu2.2018.4.13
\end{abstract}

\section{ГЛАГОЛЬНАЯ ГАСТРОНОМИЧЕСКАЯ МЕТАФОРА КАК СРЕДСТВО РЕАЛИЗАЦИИ ГАСТРОНОМИЧЕСКОГО КОДА КУЛЬТУРЫ ВО ФРАНЦУЗСКОМ ЯЗЫКЕ}

\author{
Ольга Алексеевна Дормидонтова \\ Липецкий государственный педагогический университет им. П.П. Семенова-Тян-Шанского, \\ г. Липецк, Россия
}

Аннотация. Исследование посвящено актуальной проблеме отражения в разных лингвокультурах представлений о мире во всем его многообразии. Цель статьи - охарактеризовать семантические и структурные особенности глагольной гастрономической метафоры как механизма реализации гастрономического кода французской лингвокультуры. Исследовательские задачи решены с привлечением обширного корпуса фразеологических единиц со стержневым компонентом «гастрономический глагол». Семантические особенности глагольной гастрономической метафоры рассмотрены на примере группы глаголов, обозначающих прием пищи: предложена семантическая классификация таких метафор, показано, что наибольшим разнообразием характеризуются метафоры, использованные для обозначения внешних и внутренних качеств человека, его состояния и отношений с другими людьми. Структурные особенности рассмотрены на примере группы глаго- 
лов, обозначающих разнообразные кулинарные приемы и действия: установлены когнитивные опоры таких метафор, с учетом признака переходности глагола выявлены модели и субмодели их построения, определено, что большее структурное разнообразие свойственно метафорическим конструкциям, включающим переходный глагол. Доказано, что гастрономическая метафора, номинируя широкий круг объектов, и их признаков, разнообразные процессы, состояния, является маркером французской лингвокультуры.

Ключевые слова: французский язык, лингвокультура, языковая картина мира, код культуры, метафора, гастрономическая метафора, метафорическая модель, когнитивные опоры.

Цитирование. Дормидонтова О. А. Глагольная гастрономическая метафора как средство реализации гастрономического кода культуры во французском языке // Вестник Волгоградского государственного университета. Серия 2, Языкознание. - 2018. - Т. 17, № 4. -C. 146-152. - DOI: https://doi.org/10.15688/jvolsu2.2018.4.13

\section{Введение}

Любое лингвокультурное сообщество имеет особое языковое видение мира - систему представлений об окружающей действительности, заключенных в значении разных слов и выражений данного языка [Введение в когнитивную лингвистику, 2004; Красных, 2003; Кубрякова, 2004; Тер-Минасова, 2007]. По определению В.Н. Телии, языковая картина мира - это «информация, рассеянная по всему концептуальному каркасу и связанная с формированием самих понятий при помощи манипулирования в этом процессе языковыми значениями и их ассоциативными полями, что обогащает языковыми формами и содержанием концептуальную систему, которой пользуются как знанием о мире носители данного языка» [Телия, 1988, с. 177]. Любое национальное языковое видение мира включает множество взаимосвязанных тематических национально и культурно маркированных фрагментов, отражающих, в терминологии Ю.С. Степанова, «концептуализированные предметные области» [Степанов, 1997, с. 68].

Каждый такой фрагмент действительности характеризуется специфическим набором схем, метафорических образов, символов, образующих особую систему кодов, которые в современной лингвистике рассматриваются как коды культуры, как «сетка», которую «культура набрасывает на окружающий мир, членит его, категоризует, структурирует и оценивает его» [Красных, 2002, с. 232]. Они также могут рассматриваться как «макросистема характеристик объектов картины мира», объединяющая биофакты и артефакты, физические и психические явления [Пименова, 2007, с. 79].

Коды культуры имеют высокую степень метафоричности, поскольку метафора представ- ляет собой неотъемлемую часть повседневной жизни человека и его языкового видения мира. Она является не только отражением действительности, но и средством ее создания и упорядочивания, то есть обладает моделирующей функцией, формируя представление человека об объекте и предопределяя манеру и стиль мышления о нем [Лакофф, Джонсон, 2008]. Коды культуры реализуются в языке посредством метафор. При этом их соотнесение с метафорическим значением «составляет содержание культурно-национальной коннотации, которая и придает культурно значимую маркированность не только значениям фразеологизмов или слов, но и смыслу целых текстов» [Телия, 1996, с. 219].

Представленное в этом разделе статьи понимание культурного кода является методологической основой нашего исследования.

\section{Место гастрономической метафоры в реализации гастрономического кода культуры во французском языке}

Изучая отражение в языке видения мира, свойственного французскому сообществу, нельзя не отметить моделирующую роль гастрономической метафоры и гастрономического кода культуры в целом. Гастрономия, кулинария и еда вообще занимают значительное место в культуре Франции, являясь ее своеобразным национальным маркером. Яркое подтверждение этого факта - наличие в богатом фразеологическом фонде французского языка обширного пласта гастрономической лексики во вторичных номинациях, состоящего не только из наименования продуктов питания, напитков и готовых блюд, но и наименований посуды и другой кухонной утвари.

Французская гастрономическая метафора «покрывает» все сферы реального мира: с ее 
помощью осуществляется номинация людей, предметов, действий, состояний, а также их характеристик. На основании частеречной принадлежности слов, из которых формируется метафора, можно выделить четыре вида гастрономических метафор: субстантивная, глагольная, адъективная и адвербиальная. Наиболее продуктивными и употребительными среди них являются субстантивные и глагольные метафоры. В данной статье особое внимание уделяется глагольной метафоре, поскольку во французском языке «гастрономические» глаголы являются яркой иллюстрацией значимости гастрономического кода культуры, отражая переосмысление не только базовых глаголов потребления и приготовления пищи, таких, как manger (есть), boire (пить), cuire (варить), frire (жарить), но и целого ряда глаголов, обозначающих специфические кулинарные приемы - décanter (декантировать), truffer (фаршировать трюфелями), faisander (выдерживать дичь для придания вкуса) или enrober (покрывать продукт чем-то перед приготовлением или подачей на стол).

В качестве материала для анализа были отобраны французские «гастрономические» глаголы двух тематических групп: 1) потребления пищи, 2) обозначения различных кулинарных приемов.

В работе использованы следующие лексикографические издания: Французско-русский фразеологический словарь (1963), Dictionnaire des expressions et locutions (2001), Dictionnaire alphabétique et analogique de la langue française (2006).

В рамках этих групп рассмотрим более подробно особенности метафор со стержневым компонентом «гастрономический глагол». При этом необходимо отметить, что глаголы потребления пищи представляют особый интерес для изучения гастрономической метафоры в семантическом плане, а глаголы, выражающие кулинарные приемы, - в структурном.

\section{Метафоры на основе глаголов, обозначающих потребление пищи}

К этой группе относятся такие глаголы, как: manger, boire, avaler, mâcher, dîner, souper.

Сочетаясь с косвенным дополнением или обстоятельством образа действия, неко- торые из них входят в состав метафорических образований, значение которых связано со способами приема пищи. Так, diner par coeur (букв.: 'ужинать сердцем') значит «обходиться без еды», mâcher de haut (букв.: 'жевать сверху') - «есть без аппетита», а diner d'une olive et d'un poulet (букв.: 'ужинать оливкой и курицей') - «хорошо поесть во время поста».

Во французской лингвокультуре именно базовые глаголы потребления пищи boire и manger используются для выражения фундаментальной концептуальной оппозиции «хорошо - плохо»: il y a à boire et à manger (букв.: 'имеется что пить и есть') - «здесь есть свои “за" и “против", есть и хорошие и дурные стороны».

Глаголы данной группы, обладая богатым метафорическим потенциалом, являются стержневыми элементами в широком ряду метафор, направленных на характеристику человека. Среди них было выявлено несколько семантических подгрупп.

Внешность иеловека. Например, о неестественно прямом человеке говорят: on dirait qu'il a avalé sa canne (букв.: 'такое впечатление, что он проглотил свою трость').

Манера говорить. Выявлены метафоры, характеризующие молчание: avaler son acte de naissance (букв.: 'проглотить свое свидетельство о рождении'); манеру говорить невнятно: manger ses mots (букв.: 'есть свои слова'); говорить напрямик: ne pas mâcher ses mots (букв.: 'не жевать свои слова').

Характер человека. Как правило, рассмотренные глагольные метафоры отражают отрицательные черты характера человека. Так, о трудном, неуживчивом человеке говорят il est dur à avaler (букв.: 'его трудно проглотить'). Скупой человек 'ест хлеб в своем кармане' - manger son pain dans la poche, а безвольный 'позволяет есть шерсть у себя на спине' - se laisser manger la laine sur le dos.

Отношения с другими людьми. В данной подгруппе представлены метафоры, характеризующие как дружеские, так и враждебные отношения человека к своему окружению. Выражение сильной эмоциональной привязанности к другому человеку может быть передано метафорой je le 
mangerais (букв.: 'так бы его и съел'), а проявление заботы, внимания к нему и желания помочь актуализируются в следующих метафорических образованиях: manger $q n$ de caresses (букв.: 'поедать кого-то ласками') - «осыпать ласками, окружать когото заботой, знаками внимания»; mâcher le travail à qn (букв.: 'пережевывать работу кому-либо') - «облегчить кому-то работу, помочь».

Недружественные, враждебные отношения могут быть переданы метафорой se manger le blanc des yeux (букв.: 'съесть друг у друга белок глаз') - «ссориться, грызться, выцарапать друг другу глаза».

Состояние человека. В данную подгруппу объединены метафоры, характеризующие эмоциональное, материальное и физическое состояния человека. Так, у того, кто находится в состоянии крайнего нервного возбуждения, спросят qu'est-ce que tu as mangé? (букв.: 'что ты съел?'). Трудное материальное положение может быть охарактеризовано метафорами manger son bien (букв.: 'съесть свое состояние') - «промотать состояние», manger de la vache enrageé (букв.: 'съесть мясо бешеной коровы') - «терпеть сильную нужду, бедствовать». Физическая смерть человека передается эвфемизмом aller dîner / souper avec les anges (букв.: 'отправиться ужинать с ангелами').

\section{Метафоры на основе глаголов, обозначающих приготовление пищи}

В группу глаголов, обозначающих кулинарные приемы, входят: allonger, beurrer, bouillir, cuire, décanter, dessaler, écumer, enrober, éplucher, faisander, farcir, frire, huiler, infuser, mariner, mijoter, monter, piler, poivrer, rôtir, sucrer, truffer, vinaigrer.

Когнитивным механизмом формирования метафорического значения в этой группе является актуализация когнитивных опор элементов сравнения, передающих опорное знание и репрезентирующих знание об опорном объекте [Гольдберг, 2009, с. 51]. Иными словами, знания реципиента о характеристиках действий, обозначенных глаголами приготовления пищи, выступают в качестве опор- ного признака, профилируемого в гастрономической метафоре.

Bouillir (кипеть): когнитивная опора «активный процесс». Например: avoir le sang qui bout dans les veines (букв.: 'иметь кровь, которая кипит в венах') - «быть полным сил и энергии»; bouillir d'impatience (букв.: 'кипеть от нетерпения') - «сгорать от нетерпения; с трудом сдерживать нетерпение».

Huiler (смазывать, пропитывать растительным маслом): когнитивная опора - «уменьшать силу трения». Например: huiler la pince (букв.: 'смазывать маслом щипцы') - «подмазать кого-либо, дать взятку, подкупить»; huiler les rouages (букв.: 'смазывать маслом колесный механизм') - «сглаживать трения».

Mijoter (варить, жарить на медленном огне, томить): когнитивная опора - «длительный, медленный процесс». Например: mijoter une affaire (букв.: 'томить дело') «исподволь, потихоньку подготавливать какое-либо дело».

Гастрономические метафоры в этой группе реализуют разнообразные модели и субмодели. В подавляющем большинстве случаев метафорическому переосмыслению подвергаются переходные гастрономические глаголы, реже - непереходные. Кроме этого, они приобретают метафорическое значение, становясь прономинальными, а также входя в каузативные конструкции. Рассмотрим более подробно структурные особенности таких метафор.

Метафорические конструкции с переходными глаголами разнообразны в структурном отношении и реализуют следующие модели и субмодели.

Модель 1. Переходный гастрономический глагол + прямое дополнение. Например: dessaler qn (букв.: 'обессоливать когото') - «учить уму-разуму, обтесывать»; truffer $q n$ (букв.: 'начинять кого-то трюфелями') «обмануть кого-то, обвести вокруг пальца»; faisander - прям.: «выдерживать дичь (для придания вкуса)»; перен.: faisander qn - «обманывать кого-то».

В модели с одушевленным существительным в функции прямого дополнения метафорическое значение может усиливаться или конкретизироваться за счет добавления обстоятельства образа действия. Например: 
cuire qn à petit feu (букв.: 'жарить кого-то на медленном огне') - «томить, изводить когото»; éplucher qn point par point (букв.: 'снимать с кого-то кожуру пункт за пунктом') «придирчиво критиковать кого-то, выискивать ошибки».

В случаях использования неодушевленного дополнения данная модель представлена двумя субмоделями.

Субмодель 1. Переходный гастрономический глагол + гастрономическое прямое дополнение. Например: allonger la sauce (букв.: 'разбавить соус') - 1) «говорить ни о чем, “лить воду”», 2) «делать приписки к счету»; piler du poivre (букв.: 'толочь перец') «топтаться на месте, бездействовать»; sucrer la moutarde (букв.: 'подсластить горчицу') «подсластить пилюлю»; monter le blanc en neige (букв.: 'взбивать яичный белок') «взбодрить, поднять дух».

Данная субмодель может быть расширена за счет добавления одушевленного $(\grave{a} q n)$ или неодушевленного (de qch) косвенного дополнения. Например: infuser le courage à qn (букв.: 'делать кому-то настой из храбрости') - «придать храбрости, вдохнуть в кого-то мужество»; farcir ses paroles / son discours (de citations) (букв.: 'начинять фаршем свою речь') - «украшать свою речь цитатами». При этом в субмодели «verbe + qch + à qn» в качестве неодушевленного дополнения выступает, как правило, гастрономическое существительное. Например: bouillir du lait à qn (букв.: 'кипятить кому-то молоко') - «сделать, сказать кому-либо что-либо приятное»; «угождать кому-либо, гладить по шерстке кого-либо»; frire des œufs à qn (букв.: 'жарить кому-то яйца') - «готовиться подшутить над кемлибо»; beurrer une biscotte à qn (букв.: 'смазать сливочным маслом гренок кому-то') «(по)целовать кого-либо».

Субмодель 2. Переходный гастрономический глагол + негастрономическое прямое дополнение. Например: décanter ses idées (букв.: 'декантировать, сцеживать свои мысли') - «дать себе время разобраться в чемлибо»; écumer la marmite de qn ('снимать пену с чьего-то котелка') - «быть прихлебателем у кого-либо»; enrober - прям.: «покрывать продукт чем-то перед приготовлением или подачей на стол (тестом, шоколадом, глазурью, сливками и т. п.)»; перен.: enrober la situation - «приукрашивать, смягчать ситуацию»; vinaigrer ses paroles (букв.: 'приправлять уксусом свои слова') - «язвить».

Переходные гастрономические глаголы способны принимать местоименную форму, сохраняя при этом способность к метафоризации. В прономинальном виде они являются возвратными (réfléchis) и могут использоваться либо с прямым дополнением, либо без него. Такая возможность реализуется в следующей модели.

Модель 3. Местоименный возвратный гастрономический глагол (+ прямое дополнение). Например: se beurrer (букв.: 'намазать себя сливочным маслом') / se poivrer (букв.: 'поперчить себя') - «напиться»; se sucrer (букв.: 'подсластить себя') - «получать большую часть чего-либо, наживаться»; se farcir (букв.: 'начинить себя фаршем') se farcir la mémoire de dates - «забить себе голову датами»; se farcir tout le travail «взять на себя самую сложную работу».

Модель 4. Laisser / faire + zастрономический глагол. Эта модель представлена переходными глаголами, входящими в состав каузативных конструкций. Она, как правило, бывает расширена за счет дополнений (прямых и косвенных), а также обстоятельств места. Например: faire bouillir la marmite (букв.: 'вскипятить котел') - «содержать семью, зарабатывать»; faire bouillir le sang à qn (букв.: 'вскипятить кому-то кровь') - «выводить кого-то из себя, возмущать»; laisser mariner qn (букв.: 'мариновать кого-то') «заставлять кого-то ждать»; laisser cuire qn dans son jus (букв.: 'оставить кого-то вариться в своем соку') - «оставить кого-то в затруднительном положении».

Непереходные гастрономические глаголы представляют менее наполненную группу и являются стержневым компонентом лишь одной модели.

Модель 5. Непереходный гастрономический глагол + обстоятельство места / образа действия. Например: bouillir d'impatience (букв.: 'кипеть от нетерпения') «испытывать сильное нетерпение»; on rôtit ici (букв.: 'здесь что-то жарят на огне') - «здесь очень жарко». 


\section{Выводы}

Во французском языке метафорическому переосмыслению подвергаются глаголы двух групп: обозначающие потребление пищи и разнообразные кулинарные приемы. В результате проведенного анализа было выявлено, что глагольная метафора обладает значительным семантическим и структурным потенциалом будучи антропоцентричной по суги, она преимущественно направлена на характеристику человека, реализуя при этом большое количество структурных моделей и субмоделей.

Проведенное исследование доказало, что глагольная гастрономическая метафора является важным механизмом реализации французского гастрономического кода культуры и способствует формированию языковой картины мира во французском лингвокультурном сообществе.

\section{СПИСОК ЛИТЕРАТУРЫ}

Введение в когнитивную лингвистику, 2004. Введение в когнитивную лингвистику / отв. ред. М. В. Пименова. Кемерово : Издательско-полиграфический комплекс «Графика». Вып. 4. 208 с.

Гольдберг В. Б., 2009. Художественное сравнение как модель познания // Филология и культура : Материалы VII Междунар. науч. конф. (г. Тамбов, 14-16 окт. 2009 г.). Тамбов : Издат. дом ТГУ им. Г.Р. Державина. С. 49-52.

Красных В. В., 2002. Этнопсихолингвистика и лингвокультурология. М. : ИТДГК «Гнозис». 284 с.

Красных В. В., 2003. «Свой» среди «чужих»: миф или реальность? М. : ИТДГК «Гнозис». 375 с.

Кубрякова Е. С., 2004. Язык и знание: На пути получения знаний о языке: Части речи с когнитивной точки зрения. Роль языка в познании мира. М. : Языки славянской культуры. 560 с.

Лакофф Дж., Джонсон М., 2008. Метафоры, которыми мы живем. М. : Изд-во ЛКИ. 256 с.

Пименова М. В., 2007. Коды культуры и проблема классификации концептов // Язык. Текст. Дискурс : Научный альманах Ставропольского отделения РАЛК / под ред. проф. Г. Н. Манаенко. Ставрополь : Изд-во ПГЛУ. Вып. 5. С. 79-86.

Степанов Ю. С., 1997. Константы. Словарь русской культуры. М. : Языки русской культуры. 824 с.

Телия В. Н., 1988. Метафоризация и ее роль в создании языковой картины мира // Роль человеческого фактора в языке. Язык и картина мира / отв. ред. Б. А. Серебренников. М. : Наука. С. 173-204.
Телия В. Н., 1996. Русская фразеология. Семантический, прагматический и лингвокультурологический аспекты. М. : Школа «Языки русской культуры». 288 с.

Тер-Минасова С. Г., 2007. Война и мир языков и культур: вопросы теории и практики. М. : АСТ : Астрель : Хранитель. 286 с.

\section{СЛОВАРИ}

Франиузско-русский фразеологический словарь, 1963 - Французско-русский фразеологический словарь / под ред. Я.И. Рецкера. М.: Гос. изд-во иностр. и нац. словарей. $1111 \mathrm{c.}$

Dictionnaire des expressions et locutions, 2001 Rey A., Chantreau S. Dictionnaire des expressions et locutions. Paris: Dictionnaires LE ROBERT. 1322 p.

Dictionnaire alphabétique et analogique de la langue française, 2006 - Rey-Debove J., Rey A. Le Nouveau Petit Robert. Dictionnaire alphabétique et analogique de la langue française. Paris : Dictionnaires LE ROBERT. 2949 p.

\section{REFERENCES}

Pimenova M.V. (ed.), 2004. Introduction to Cognitive Linguistics. Kemerovo, Grafika Publ., iss. 4.208 p.

Goldberg V.B., 2009. Fiction Analogy as a Cognitive Model. Filologiya i kultura: Materialy VII Mezhdunar. nauch. konf. (g. Tambov, 1416 okt. 2009 g.). Tambov, TGU im. G.R. Derzhavina Publ., pp. 49-52.

Krasnykh V.V., 2002. Ethno-Psycholinguistics and Cultural Linguistics. Moscow, Gnozis Publ. 284 p.

Krasnykh V.V., 2003. "As if You Are One of the Guys": Myth or Reality? Moscow, Gnozis Publ. 375 p.

Kubryakova E.S., 2004. Language and Knowledge: On the way to Getting Information about the Language: Parts of Speech from the Cognitive Viewpoint. The Role of Language in the Cognition of the World. Moscow, Yazyki slavyanskoy kultury Publ. 560 p.

Lakoff J., Johnson M., 2008. Metaphors we L=ive by. Moscow, LKI Publ. 256 p. (in Russian).

Pimenova M.V., 2007. Culture Codes and the Problem of Concepts' Classification. Manaenko G.N., ed. Yazyk. Tekst. Diskurs: Nauchnyy almanakh Stavropolskogo otdeleniya RALK. Stavropol, Izd-vo Severo-Kavkazskogo federalnogo un-ta, pp. 79-86.

Stepanov Yu.S., 1997. Constants. The Dictionary of Russian Culture. Moscow, Yazyki russkoy kultury Publ. 824 p. 
Teliya V.N., 1988. Metphorization and Its Role in the Global Worldview Formation. Serebrennikova B.A., ed. Rol chelovecheskogo faktora $v$ yazyke. Yazyk i kartina mira. Moscow, Nauka Publ., pp. 173-204.

Teliya V.N., 1996. Russian Phraseology. Semantic, Pragmatic and Linguocultural Aspects. Moscow, Yazyki russkoy kultury Publ. 288 p.

Ter-Minasova S.G., 2007. War and Peace of Languages and Cultures: Theoretical and Applied Issues. Moscow, AST Astrel; Khranitel Publ. 286 p.

\section{DICTIONARIES}

Retsker Ya.I. (ed.), 1963. French-Russian Dictionary of Phraseology. Moscow, Gos. izd-vo inostr. i nats. slovarey. $1111 \mathrm{p}$.

Rey A., Chantreau S., 2001. Dictionnaire des expressions et locutions. Paris, Dictionnaires LE ROBERT. 1322 p.

Rey-Debove J., Rey A., 2006. Le Nouveau Petit Robert. Dictionnaire alphabétique et analogique de la langue française. Paris, Dictionnaires LE ROBERT. 2949 p.

\section{Information about the Author}

Olga A. Dormidontova, Candidate of Sciences (Philology), Associate Professor of Department of French and German Languages, Lipetsk State Pedagogical P. Semenov-Tyan-Shansky University, Lenina St., 42, 398020 Lipetsk, Russia, olgadormi@mail.ru, https://orcid.org/0000-0001-9840-5660

\section{Информация об авторе}

Ольга Алексеевна Дормидонтова, кандидат филологических наук, доцент кафедры немецкого и французского языков, Липецкий государственный педагогический университет им П.П. Семенова-Тян-Шанского, ул. Ленина, 42, 398020 г. Липецк, Россия, olgadormi@mail.ru, https://orcid.org/0000-0001-9840-5660 